BULLETIN Bulletin hispanique

HISPANIQUE Université Michel de Montaigne Bordeaux

111-1 | 2009

Varia

\title{
Modelos franceses y neoclasicismo en la prensa española de principios del siglo XIX (1801-1805)
}

José Checa Beltrán

\section{OpenEdition}

Journals

Édition électronique

URL : http://journals.openedition.org/bulletinhispanique/916

DOI : 10.4000/bulletinhispanique.916

ISSN : 1775-3821

Éditeur

Presses universitaires de Bordeaux

Édition imprimée

Date de publication : 1 juin 2009

Pagination : 141-164

ISBN : 978-2-86781-586-7

ISSN : 0007-4640

\section{Référence électronique}

José Checa Beltrán, « Modelos franceses y neoclasicismo en la prensa española de principios del siglo XIX (1801-1805) », Bulletin hispanique [En ligne], 111-1 | 2009, mis en ligne le 01 juin 2012, consulté le 20 avril 2019. URL : http://journals.openedition.org/bulletinhispanique/916 ; DOI : 10.4000/bulletinhispanique.916 


\title{
Modelos franceses y neoclasicismo en la prensa española de principios del siglo XIX (1801-1805)
}

\author{
José Checa Beltrán \\ Centro de Ciencias Humanas y Sociales. CSIC. Madrid
}

Ce travail étudie la réception des écrivains, critiques et théoriciens français dans la presse espagnole la plus représentative des premières années du XIXe siècle. L'analyse de cette réception, en Espagne, des auteurs français, tantôt comme modèles, tantôt comme contre-modèles, contribue aussi à éclairer la discussion sur l'adhésion de la pensée littéraire espagnole de ces années là aux idées du Classicisme ou du Préromantisme.

Este trabajo estudia la recepción de los literatos, criticos y teóricos franceses en la mejor prensa española de principios del siglo XIX. El análisis de esta recepción española de autores franceses, como modelos o contramodelos, contribuye, además, al esclarecimiento de la discusión sobre la adscripción, neoclásica o prerromántica, del pensamiento literario español de aquellos años.

This paper deals with the reception of the French literary writers, critics and theorists by the most important Spanish Press in the early nineteenth century. The analysis of the Spanish perception of French authors - used either as models or as counter-models also helps to shed light on the debate about the support of Spanish literary thinkers for Neoclassic or Pre-Romantic ideas in those years.

Mots-clés: Presse littéraire - Néo-classicisme - Préromantisme - Modèles littéraires - Classicisme français - Pensée littéraire du XIX siècle.

$B H i$, Tome 111, n 1 - juin 2009 - p. 141 à 164. 
$\mathrm{R}$ ESULTA ya tópico referirse al auge de las investigaciones dieciochistas en Espańa durante las últimas décadas. También el ámbito concerniente al presente trabajo, relativo a la literatura y el pensamiento literario, ha gozado de un número considerable de estudios recientes, gracias a los cuales se conoce mejor tanto la literatura como la teoría y la crítica literaria españolas del siglo Ilustrado. No es éste el lugar para enumerar esas aportaciones ${ }^{1}$, sí para referir, como prolegómeno, que la historiografía dieciochista posee un conocimiento bastante satisfactorio acerca de asuntos como la relación entre reforma política y reforma literaria, el debate entre neoclásicos y barrocos, géneros literarios, teatro y sociedad, paralelos de lenguas, modelos literarios, antiguos y modernos, o de conceptos como el de imitación, verosimilitud, docere-delectare, res-verba, natura-ars, poesía y literatura, belleza, sublime, ficción, etc. A pesar de ello, también existen ámbitos temáticos y cronológicos de la época neoclásica insuficientemente estudiados. Por ejemplo, el relativo al papel del clasicismo francés, como modelo o contramodelo, entre los críticos españoles de principios del XIX, objetivo de este trabajo. Se trata de una cuestión, y unos años, que no se contemplan en tres importantes contribuciones recientes (Aymes, 1996 y 1997; Larriba, 1998), ocupadas de ańos contiguos a 1801-1805 y de cuestiones diferentes, aunque colindantes, a las que aquí analizamos ${ }^{2}$.

La elección de modelos literarios es uno de los temas fundamentales que la historiografía literaria tiene que considerar. Es archiconocido que el debate entre neoclásicos y barrocos durante el siglo XVIII español tiene como referencia última la oposición entre quienes defienden como dechados de estilo a autores como Garcilaso, Fray Luis de León, los Argensola, etc., y quienes proponen como ejemplo la literatura barroca de Góngora, Lope, Calderón, etc. La elección de unos modelos, y el consiguiente rechazo de otros, supone la existencia de una teoría literaria previa que avala esa opinión, y, si no existiera, impone la necesidad de elaborar un aparato crítico y teórico que justifique dicha elección.

1. Una bibliografía crítica bastante completa puede consultarse en mi libro Pensamiento literario español del siglo XVIII (Checa: 2004, págs. 333-345). Junto a esta bibliografía secundaria, puede hallarse en esta misma obra un capítulo sobre bibliografía primaria: «Bibliografía de teoría literaria española del Siglo Dieciocho» (págs. 319-327)

2. Es justo citar aquí el pionero y meritorio trabajo de Georges Le Gentil, que no se ocupó del Memorial Literario pero sí de Variedades: esta revista «nous permet de constater, au point de vue littéraire [...], la pénétration de l'influence française [...], de l'influence anglaise $[. .$.$] , de l'influence allemande» (págs. 1-2). En mi opinión, la influencia francesa es$ abrumadoramente mayor que la de Inglaterra y Alemania. 
No voy a narrar aquí la evolución del gusto literario español durante el siglo XVIII, el desarrollo de su crítica e historia literaria, el significado de sus poéticas (Checa Beltrán: 1996 y 1998), la implantación de sus géneros literarios (François Lopez: 2000) o las implicaciones nacionalistas en la búsqueda de un canon (Rodríguez Sánchez de León: 1999, y Checa Beltrán: 2002). Sí quiero estudiar algo que, como digo, está pendiente de respuesta: el papel de Francia como referencia literaria en la prensa espańola de los primeros ańos del XIX, lo que significa, por añadidura, enfrentarse a la pregunta sobre la implantación del neoclasicismo en España durante unos controvertidos años que muchos historiadores han tildado de prerrománticos o románticos.

Sabemos que Francia -su literatura, su cultura, sus costumbres- estuvo omnipresente en la España dieciochesca (al igual que en toda Europa). Sabemos de los debates entablados en la primera mitad del siglo entre partidarios y detractores de la traducción de textos franceses. Sabemos del triunfo de los partidarios del aggiornamento español, de la necesidad de introducir en Espańa -mediante la traducción de libros franceses, sobre todo- los avances registrados en la Europa culta durante un período en que el aislamiento y la autarquía imperaron en nuestro país. La consecuencia de ello fue la enorme cantidad de libros franceses traducidos al español durante el siglo XVIII.

Pero esta favorable actitud hacia la traducción de obras francesas se fue invirtiendo a partir de aquel célebre artículo de Masson de Morvilliers en la Encyclopédie Méthodique (François Lopez: 1999) y, poco después, por efecto de la Revolución Francesa. En esas dos últimas décadas del Siglo Ilustrado, muchos autores españoles se rebelan contra la traducción de obras galas, aduciendo que muchas de ellas son innecesarias y que las traducciones del francés están contribuyendo decisivamente a la corrupción de la lengua española. Así, Vargas Ponce propone (1793: págs. 191 y 37) que la Academia Española, «avocándose el conocimiento y censura de las traducciones», cree una "Mesa Censoria» que las juzgue y decida sobre su publicación. Asimismo, subraya que el principal culpable del empobrecimiento del castellano ha sido el idioma francés, «mezquino y pobre, monótono y seco y duro, sin fluidez, sin copia, sin variedad».

Es indudable que durante gran parte del siglo XVIII muchos autores franceses fueron reconocidos como modelos literarios o como referencias teóricas imprescindibles entre los autores neoclásicos españoles. Pero ese carácter modélico de Francia se resquebraja entre la intelectualidad española de finales del XVIII debido a los acontecimientos políticos señalados y, anotemos también, al auge del emergente nacionalismo cultural de toda 
Europa. Sin embargo, sabemos poco sobre cuál fue la actitud de los autores espańoles (intelectuales, literatos, periodistas...) ante la cultura y la literatura francesa en los primeros ańos del XIX, momentos en que la alianza política entre España y Francia se ha restablecido, y sería previsible pensar que, al no haber motivos institucionales para la enemistad, las opiniones favorables a Francia podrían expresarse públicamente sin temor a represalias. Nada mejor que el análisis de los periódicos españoles más importantes de entonces ${ }^{3}$ para averiguar la actitud ante Francia como modelo cultural y, al mismo tiempo, para aportar datos acerca de las posiciones españolas respecto al neoclasicismo, en un momento en que la historiografía habla de prerromanticismo y de luchas entre dos grupos, moratinistas y quintanistas, sobre cuya identidad política y literaria no se han puesto de acuerdo los historiadores (Checa: 1998, págs. 283-310). Estas cuestiones serán objeto de atención en las próximas páginas.

En efecto, desde el punto de vista diplomático, las relaciones hispanofrancesas durante las dos últimas décadas del siglo XVIII se vieron enturbiadas por el incidente provocado por Masson con su artículo «¿Qué se debe a España?» (1784), de la Encyclopédie Méthodique, y, posteriormente, por las consecuencias de la Revolución Francesa. Como es sabido, el citado artículo, donde se sostenía que Espańa no había aportado nada a la cultura occidental, provocó un incidente diplomático entre los dos países y desencadenó una serie de apologías -muchas de ellas propiciadas desde instancias gubernativas- de las aportaciones españolas a la cultura europea, que incluían duros ataques a Francia, país modélico para muchos escritores españoles de entonces y de las décadas anteriores.

Pero también en los años ochenta hubo en España intelectuales que, ajenos a aquel triunfalismo apologético, artificioso e inconsistente, y sin abandonar su actitud francófila, reclamaron una mayor profundización en las reformas políticas y culturales que los Borbones españoles habían iniciado y que durante aquellos años estaban en franco retroceso. Obviamente, estos últimos escritores no pudieron manifestarse con la misma libertad y facilidad con que lo hicieron los apologetas, favorecidos, como digo, por las instituciones españolas.

3. Para la redacción de este trabajo he tomado en consideración los dos principales periódicos españoles de la época según la opinión general de la historiografía literaria: Variedades de Ciencias, Literatura y Artes (1803-1805) -impulsado y capitaneado por Manuel José Quintana-, que he examinado en su totalidad, y el Memorial Literario (1784-1808), del que he investigado los años 1801-1805, en que se publicó con el título de Memorial Literario o Biblioteca Periódica de Ciencias y Artes. Sobre los redactores y directores del Memorial, véase Urzainqui, 1990. 
La Revolución y el consiguiente "cordón sanitario" determinaron que las cosas continuasen en un estado similar al de los años ochenta: Francia siguió siendo criticada como pocas veces lo fue durante el siglo XVIII, por motivos políticos, pero también por el cansancio de muchos españoles ante el inamovible desprecio de sus vecinos, incapaces de reconocer algunos méritos en el legado cultural español, o ciertos progresos en la producción intelectual española de la segunda mitad del Siglo Ilustrado.

Por otra parte, parece que en los ańos del cambio de siglo es vigorosa la anglomanía española. Según Moreno Alonso (1997: pág. 49), los años en que vivió Lord Holland (1773-1840) coinciden «con un período histórico en que en toda Europa, y de forma particular en España, se produce una extraordinaria pasión por Inglaterra que, por su intensidad, carece en verdad de precedentes».

Aquella extendida opinión antifrancesa, además, coincidió cronológicamente con el cansancio de otros países europeos ante la larga hegemonía cultural gala, que había sabido imponer su lengua y sus principios artísticos, los del clasicismo, en los últimos tiempos. Frente a un gusto clasicista, donde la superioridad literaria francesa era incontestable, frente a una cultura libresca, donde se reconocía a Francia la hegemonía, Europa desenterró el gusto por la cultura oral, lo popular, lo genuino de cada país. Ese nacionalismo literario llega también a España donde no sólo se «descubre» el valor de nuestros romances y de la olvidada cultura medieval, sino que también comienza a ser reivindicado, aún tímidamente, nuestro teatro barroco, incluso por parte de reconocidos autores de pensamiento inequívocamente clasicista.

Así pues, a finales del XVIII comienza a extenderse la idea de que la mejor manera de acabar con el «imperialismo» cultural francés era mediante la reivindicación del valor de lo propio, de aquello que estaba olvidado o enterrado, y de aquello que había sido menospreciado precisamente por su disintonía con el gusto francés, es decir, nuestra literatura barroca. La oposición a Francia, pues, se plasma en el ámbito literario español en una serie de opiniones que afectan no sólo a la traducción y la lengua, sino también a los modelos y a la consideración sobre el neoclasicismo y el barroco. En la última década del XVIII pueden leerse opiniones como las del neoclásico Pedro Estala, acerca de nuestros dramaturgos del Siglo de Oro, en las que reivindica para ellos la paternidad del teatro moderno, quitando ese mérito, reconocido hasta entonces, a los franceses: «creo haber probado que la tragedia antigua y la moderna son dos especies muy distintas, que se diferencian en sus caracteres más principales, que la tragedia griega no puede adaptarse a nuestro actual teatro, que para éste es mucho más ventajosa la moderna, perfeccionada por Corneille e inventada por los espańoles en el 
siglo XVII». Y añade: «Molière se elevó a la mayor perfección de la comedia, imitando a los españoles, como diré en otro discurso; el gran Corneille por el mismo medio se hizo el padre de la tragedia moderna» (1793: págs. $48 \mathrm{y}$ 37).

Aquellas opiniones tan radicales contra las traducciones desde el francés, contra la calidad del idioma galo, contra el desprecio hacia el teatro barroco español -que de repente aparece como el padre del teatro moderno- y, en definitiva, contra todo lo relacionado con Francia, va a cambiar en los primerísimos años del siglo XIX, al menos en dos de los más importantes periódicos que se publicaron entonces en España, el Memorial Literario ${ }^{4}$ y Variedades de Ciencias, Literatura y Artes. Me ha parecido oportuno acudir precisamente a estos dos periódicos porque son, sin duda, los más representativos del gusto literario español de entonces y de su actitud ante Francia y el clasicismo.

Existen datos que inducen a pensar que moratinistas y quintanistas -los dos bandos literarios de la época (Alcalá Galiano: 1913, pág. 63)- podían haberse servido de estos periódicos para dirimir en ellos sus diferencias ${ }^{5}$. Quintana fue el principal inspirador y redactor de Variedades, en cuyas páginas escribió una reseña de La mojigata de Moratín donde, a pesar del tono moderado y elogioso, aparecen ciertas críticas y se advierte cierto malestar de fondo entre los dos autores. Asimismo, José María de Carnerero firmó en el Memorial Literario una reseña del Pelayo de Quintana, donde junto a indudables elogios y un tono igualmente moderado, sostiene que Leandro Fernández de Moratín «sin la menor disputa, es el maestro de nuestra escena cómica» (VI: 244).

Aquella oposición entre moratinistas y quintanistas incluía, como es sabido, la elección como autoridad teórica del francés Batteux (Urzainqui: 1989) o del escocés Blair, respectivamente, representantes de un clasicismo francés el primero, y de ciertas innovaciones teóricas contrarias al clasicismo, el segundo. Si a ello sumamos la relativa heterodoxia del grupo de Quintana, y su preferencia por un gusto poético no sólo francés, sino también inglés o alemán ${ }^{6}$, podría pensarse a priori, como digo, que en estos periódicos

4. Escribía Menéndez Pelayo (1974: I, págs. 1348-1349) que el Memorial era la «verdadera revista crítica de aquella época», presentó en sus páginas «el más extenso inventario de la literatura de aquel período, y el más exacto reflejo de las ideas que en tan largo tiempo se disputaron entre nosotros la dominación del gusto».

5. Véase Urzainqui (1990: pág. 513).

6. Tras elogiar la poesía de Meléndez, Jovellanos y Cienfuegos, escribía Quintana, en «Sobre la poesía castellana del siglo XVIII», que estos «habían introducido en la poesía española un gusto extraño, que parece tomado del francés, del alemán y del inglés» (1946: pág. 157). 
pudieron haber dirimido sus diferencias estos dos grupos, y que esas diferencias contuvieran una distinta actitud ante Francia. Adelanto ya que, tras mi investigación, he concluido que no fue así: a pesar de una posición algo más favorable a Francia del Memorial, también Variedades presenta una línea sumamente elogiosa para con el país vecino. Sólo varían ciertos matices y ciertas elecciones - dentro de una general coincidencia ante Francia y el clasicismo- en estos periódicos de años "prerrománticos», uno seguidor de un neoclasicismo academicista, incluso dogmático, y otro representante de un neoclasicismo heterodoxo, partidario de ciertos cambios literarios.

Pero veamos ya los detalles de los elogios y críticas que recibe Francia en las páginas literarias de estos periódicos, en los que, por motivos obvios, ocupan un lugar muy importante las dedicadas al teatro, siendo mucho menor la atención que reciben otros géneros literarios como la novela o la lírica. Decía Menéndez Pelayo que las secciones trabajadas con mayor esmero «y que daban carácter al Memorial, eran el catálogo bibliográfico-crítico de las obras que iban publicándose, y la revista de teatros» (1974: I, pág. 1349). Pues bien, gran parte de las obras reseñadas en el Memorial son francesas, unas comentadas a partir de su versión original y otras según su traduccción castellana. En la sección «Revista de teatros», además de noticias sobre las últimas obras publicadas, los lectores españoles recibían información de lo que se representaba en teatros de París, como el de la «Puerta de San Martín», el «Teatro de la Emperatriz, de la calle de Louvois», el «Teatro de la Ópera Cómica, calle de Faideau», etc., (VI: 193-195), información que no se proporcionaba respecto de ninguna otra capital europea.

Una simple ojeada al «Índice» de este periódico nos permite comprobar que, junto a las secciones de «literatura española» y "teatro español», existen otras denominadas «literatura francesa» y «teatro francés». Ningún otro país goza de secciones similares ${ }^{7}$. Asimismo, gran parte de las obras comentadas en la sección de «Noticia crítica de obras nuevas» son francesas, algunas sin traducir al español. Igual sucede en las secciones de "Historia», «Viajes», "Geografía», Moral», etc. Por el contrario, muy pocas noticias se dan del ambiente literario inglés, italiano o alemán. Además, las escasas informaciones que aparecen sobre autores u obras de estos países se ofrecen frecuentemente con motivo de su traducción al francés. Por otra parte, es

7. Si dejamos a un lado lo estrictamente literario, comprobaremos que existe una importante sección -ocupa un muy considerable número de páginas en el conjunto del periódico- titulada «Instituto Nacional de Francia», donde se dan variadas y documentadas noticias acerca de las reuniones que en ese instituto francés celebran distintas comisiones sobre astronomía, química, mineralogía, filosofía, medicina, física, anatomía, etc. 
muy significativo que en el conjunto de Variedades, y por lo que respecta al ámbito de la literatura, se reseñen 10 obras francesas, ocho españolas, cuatro inglesas y una alemana.

\section{FUENTES TEÓRICAS}

Normalmente, nuestros periodistas redactan sus reseñas y artículos literarios sin explicitar sus referentes teóricos -que suelen ser los propios del neoclasicismo-, pero cuando lo hacen suelen ser teóricos franceses los mencionados, casi nunca de otra nacionalidad, ni siquiera españoles. Es un hecho llamativo, ya que los críticos españoles disponían de las obras de Luzán, Díez González, Estala, Andrés y otros, donde podían hallar los apoyos necesarios para aquello que defendían. Sobre todo, llama la atención la ausencia de Luzán, autor del mejor tratado de poética en español, muy seguido en la España de los siglos XVIII y XIX.

En el Memorial Literario el teórico francés más citado es La Harpe y su Curso de Literatura. Junto a la reproducción monográfica de las ideas de este autor sobre algún asunto dramático - por ejemplo sus opiniones acerca de la tragedia urbana (V: 317)-, y junto a la utilización de algunas ideas sueltas sobre la comedia, tragedia, etc., a veces se reproducen directamente sus opiniones de una determinada obra. Así sucede, por ejemplo, en la crítica a la comedia El vano humillado de Destouches, donde el anónimo crítico español aclara que para su comentario se servirá de "algunas reflexiones del célebre La Harpe» (III: 207). Sucede lo mismo en una extensa reseña, de doce páginas, sobre la comedia La esposa delincuente de Beaumarchais, en la que el reseñador español, Olive, escribe: "como el mayor número de nuestros lectores tendrá muy poca o ninguna idea del autor y de la obra, no le será desagradable el que amenicemos este artículo con una breve noticia del uno y de la otra, concluyendo con el juicio de la pieza sacado del curso de literatura de La Harpe» (IV: 21-33). De igual manera, el autor anónimo de la crítica sobre las comedias El padre de familias y Beverley escribe: «he creído sería conveniente el traducir aquí lo principal que acerca [de estas obras] dice La Harpe en su curso de literatura» (V: 289).

Pero La Harpe también sirve como fuente crítica para obras de otros géneros. Así, Olive elogia el "poema de las estaciones» de Saint Lambert (V: 22), reproduciendo diversos fragmentos de la citada obra del teórico francés. Cuando La Harpe muere, el Memorial le dedica una necrológica, en la que el periodista español (Olive) escribe: «como crítico es muy juicioso, y tal vez el más sabio que su nación ha tenido en estos tiempos [...]. 
Conoce profundamente el arte y lo aplica con acierto en los análisis que de las composiciones literarias forma, y pudiera tal vez convenirle el título de Quintiliano francés que algunos le dan por sus excelentes reflexiones sobre los autores antiguos, y por el bello cuadro que ha formado del siglo de Luis XIV» (V: 26-27). Respecto a su Curso de Literatura añade que, a pesar de ser una obra "voluminosa y pesada», está «llena de excelentes artículos, la mejor tal vez de cuantas sobre esta materia se han publicado en Francia, y sin duda la más erudita, la más completa y metódica» $(\mathrm{V}: 27)^{8}$.

Otra de las fuentes teóricas del Memorial es la Encyclopédie francesa. En la reseña (IV: 250) sobre la comedia El gusto del día (de Miñano), que es un mero pretexto para que su anónimo autor se extienda en reflexiones teóricas sobre el carácter y la historia de la comedia, se acude al correspondiente artículo de la Encyclopédie, de Marmontel, sobre el arte cómico, reproduciendo y suscribiendo las opiniones que el autor francés defiende.

Marmontel es precisamente uno de los teóricos más socorridos en Variedades, y no sólo en sus ideas sobre el género dramático. En la reseña sobre los Principios de Retórica y Poética de Sánchez Barbero, se alude positivamente al hecho de que Sánchez siguiera en su capítulo sobre el estilo las doctrinas de Marmontel, Condillac y Du Broca (VII: 47), y se subraya el acierto en seguir a Marmontel en la definición de la poesía (VII: 109).

En Variedades también acuden a autoridades francesas para sustentar ciertas teorías sobre géneros líricos. En el artículo «Del idilio y de la égloga», Quintana reconoce que sobre este asunto "Fontenelle, Lamothe, Blair, Marmontel y otros han apurado cuanto puede decirse de la materia» (III: 99); en esta disertación, además de citar a Boileau, sigue en gran medida los Elementos de literatura de Marmontel.

Por otra parte, bastantes de las reseñas aparecidas en el Memorial Literario están tomadas de la Década filosófica francesa. Los periodistas españoles no tienen ningún recato en reconocer que sus críticas acerca de determinadas obras dramáticas, líricas o de teoría literaria proceden de esa revista gala. Así, la traducción al francés de Las estaciones de Thomson, hecha por J. Poulin, queda reflejada en el periódico español según la crítica negativa que anteriormente apareciera en la Década (IV: 178). A veces el crítico español intenta disimular esa gran fidelidad a la revista francesa mostrando discrepancias en algunos puntos. Por ejemplo, en la crítica a Ophis, tragedia

8. La versión original de esta obra de La Harpe fue premiada por la Real Academia Sevillana de Buenas Letras en un concurso de 1804 para elegir el mejor «Plan filosófico de unas instituciones de Bellas Letras» (ver Urzainqui: 1997, pág. 57). En este interesante artículo, la profesora Urzainqui desvela los autores franceses que influyeron en la teoría dramática espańola del siglo XVIII. 
de Lemercier, dice el periodista español que «los autores de la Década filosófica hallan en esta tragedia muchas bellezas, aunque también notan grandes defectos; pero nosotros sólo hemos encontrado los últimos» (IV: 288). Pero la Década no sólo sirve como guía en la reseña de obras literarias: en la sección de «Metafísica» (V: 296-300), por ejemplo, se incluye un comentario a una Teoría de la imaginación cuyo autor reconoce que para su exposición se ha basado en la citada publicación francesa.

También procede de dicha revista una reseña en la que el autor francés critica a Inglaterra. Se trata de la noticia de la publicación en francés del Tableau de la Grande-Bretagne o Cuadro de la Gran Bretaña, de la Irlanda y de las posesiones inglesas en las cuatro partes del mundo. El crítico del Memorial escribe que «según el juicio de los autores de la Década Filosófica, esta obra es la más completa e instructiva que se puede desear para conocer el estado político, comercial y moral de la Gran Bretańa», país que no sale muy bien parado en esta obra porque -según dice el articulista- junto a ciertas virtudes manifiesta grandes defectos: «reúne las cualidades más opuestas y los más notables contrastes de elevación y de bajeza, de nobleza y venalidad, de humanidad y dureza [...], nación últimamente que por su inquietud, avaricia y ambición, no desea sino guerra, y que sin embargo funda exclusivamente su felicidad en el comercio, que se apoya esencialmente en la paz» (V: 141142). El autor español de la reseña no se opone a lo afirmado por el crítico galo, haciendo así causa común con Francia en contra de Inglaterra, enemigo político de ambos países en aquellos años. La Década también sirve al Memorial como fuente para la reproducción de ciertas piezas literarias cortas previamente publicadas en el periódico francés: por ejemplo, un «cuento oriental, sacado de la Década Filosófica» titulado Las doce dervices (V: 270).

En síntesis, no hay referencias a fuentes teóricas de otros países, ni siquiera a Luzán u otros teóricos españoles. El motivo de esta elección podría radicar en el prestigio que conferían los autores franceses, en la «modernidad» de estos frente a la «antigüedad» de Luzán, en la pretensión de cosmopolitismo de que hacían gala ambos periódicos, en el neoclasicismo militante de nuestros periodistas, en el afrancesamiento de la intelectualidad espańola de entonces y en el favorable clima político entre los dos países, que necesariamente había de reflejarse en la prensa del momento.

\section{Modelos Literarios}

En cuanto a los modelos literarios, es indudable que los literatos franceses ocupan el primer lugar -muy por delante también de los autores castellanos- en los dos periódicos estudiados. El Memorial Literario presenta 
a determinados autores franceses como ejemplos máximos, clásicos en sus respectivos géneros, auténticas referencias universales. En teatro, los modelos indiscutibles son Racine, Molière, Voltaire y Corneille, aunque sobre este último no existe unanimidad, debido a la polémica que hubo de sufrir en vida acerca de su infracción de las reglas en El Cid.

Por lo que se refiere al teatro del siglo XVIII, el crítico de El vano humillado, de Destouches, parafrasea y corrobora ciertas opiniones acerca del teatro galo defendidas por La Harpe, quien estimaba que si bien las comedias francesas dieciochescas no alcanzaron la altura excepcional de las escritas en el siglo XVII -debido, sobre todo, a la talla de Molière-, las tragedias del Siglo Ilustrado sí pueden equipararse a la centuria anterior, merced a la aportación de Voltaire, autor de «una multitud de obras maestras, que en nada ceden a las del siglo anterior» (III: 207).

Pero nuestros críticos no muestran una pedestre y ciega admiración por todo el teatro francés, cuyas obras saben discriminar, siempre desde una perspectiva claramente neoclásica: en la reseńa de Olive sobre el Origen, épocas y progresos del teatro español, de Manuel García de Villanueva Hugalde y Parra, el periodista critica al autor de esta obra precisamente por su incompetencia a la hora de distinguir los mejores autores dramáticos franceses; así, muestra su desacuerdo ante afirmaciones como ésta: «Corneille y Molière elevaron el teatro a aquel punto de grandeza que Racine y Regnard sostuvieron, y que después se extendió en las obras de Crebillon, Voltaire, Destouches, La Chaussée, Marivaux, Saint-Foix, Boissy, etc.». El periodista considera que en estas palabras hay muchos desatinos: primero, «todos mis paisanos convienen en que la perfección del arte sólo en Racine se halla». Segundo, Corneille y Molière no pueden ser colocados a idéntica altura; mientras que Molière es verdaderamente autor de comedias perfectas, Corneille «no tiene una tragedia que rigurosamente se pueda llamar tal». Evidentemente, nuestro crítico se adscribe a aquella corriente dogmática que se ensañó en la obra de Corneille porque no se ajustaba a unas estrictas reglas neoclásicas. Tercero: «sólo Voltaire sostuvo la gloria de Racine», Regnard y Crebillon son inferiores, mientras que Chaussée y Marivaux «deberán estar avergonzados entre tan grandes señores» con quienes aquí se les coloca (IV: 140-141). Resumiendo, la tragedia tiene sus máximos modelos en Racine y Voltaire, mientras que Molière es el solo ejemplo para la comedia.

El entusiasmo por el teatro francés se manifiesta igualmente en Variedades. Quintana considera como modelo esencial a Racine; por ejemplo cuando, a propósito de la traducción de Blair a cargo de Munárriz, sostiene que el gusto se perfecciona con el ejercicio, al igual que «las otras facultades intelectuales 
y físicas»; así, quienes se entretienen con «la poesía y música de una tirana» (en alusión a la popular cómica), nunca podrán comprender «el mérito que hay en la Athalia de Racine» (V: 351).

En la reseña a La Muerte de Abel, tragedia de Legouvé -traducida al castellano por Antonio Sabiñón ${ }^{\text {- }}$, escribe Quintana que "por el espacio de más de un siglo han estado los franceses ańadiendo perfecciones al arte de la tragedia. Los mayores talentos la han cultivado; un público apasionado por los espectáculos los animaba [...]», hasta el punto de que "aquel admirable teatro» ha enriquecido "el arte con tantas obras clásicas» (I: 44-45). Su juicio sobre esta reciente obra no es menos elogioso: se trata de «una de las mejores composiciones que se han hecho en Francia, después de las tragedias clásicas de sus hombres grandes» (I: 52).

La admiración hacia la dramaturgia francesa se manifiesta también respecto de autores quizás de segunda fila. Por ejemplo, Quintana firma en Variedades una reseńa sobre El reconciliador, comedia original de Demoustier, traducida al castellano por Enciso Castrillón, donde, aun señalando ciertos defectos, elogia al dramaturgo francés y compara ventajosamente su obra con la traducción espańola: «es palpable la distancia y la inferioridad que hay en los versos castellanos respecto de los franceses, ya en la delicadeza, ya en el tono», y precisa que en la versión castellana desaparecen aquel «lenguaje natural que adorna y suaviza la verdad sin alterarla», así como la pintura de los caracteres de ciertos personajes (III: 371-373).

Asimismo, en la reseńa sobre El vano humillado de Destouches, el anónimo crítico del Memorial considera a Destouches como «uno de los primeros cómicos del siglo XVIII en el orden del tiempo y del mérito» (III: 208). También Beaumarchais es elogiado por su inteligencia, «su ingenio y sus gracias». El crítico Olive escribe sobre El casamiento de Fígaro que «ni en el teatro moderno, ni aun tal vez en el antiguo, se halla un drama que tanto ruido haya hecho, ni que haya logrado tantos aplausos» (IV: 21-33).

\section{BARROCO-NEOCLASICISMO}

Si examinamos cómo se compara en la prensa elegida el teatro clasicista francés con los heterodoxos teatros español e inglés del siglo XVII, llegamos a la misma conclusión: los periódicos que estudiamos, lejos de cualquier manifestación de nacionalismo literario, se inclinan nítidamente a favor del teatro francés ${ }^{10}$.

9. Hay otra traducción de Magdalena Fernández y Figuero, ambas prohibidas por la Inquisición en 1806 (Rodríguez Sánchez de León, 1999: 146)

10. Es algo que se advierte igualmente en el conocido Teatro Nuevo Español (1800-1801), 
Decía Menéndez Pelayo que el Memorial del último período (18011808) se españolizó mucho, opinión esta que, evidentemente, merece ser puntualizada: el teatro francés siempre está considerado allí como muy superior al español. Un ejemplo de esto lo hallamos en la reseña de los Principios filosóficos de literatura, o curso razonado de Bellas Letras y Artes de Batteux, traducidos y comentados por García de Arrieta. El articulista, Olive, es contrario a la posición nacionalista de Arrieta cuando escribe que «la España tiene la gloria de haber sido la inventora de un nuevo teatro imitado después por las demás naciones cultas de Europa» (IV: 84). El crítico del Memorial responde a Arrieta: «No sé qué entenderá aquí nuestro autor por un nuevo teatro. El único que entre los modernos ha merecido verdadera estimación, y al que se puede dar el epíteto de nuevo teatro, es el de Corneille, Racine y sus imitadores»; aunque aceptáramos que los españoles hubieron formado un «nuevo género de teatro» -continúa el periodista-, éste era tan «monstruoso y desarreglado, que, en general y rigurosamente hablando, no pertenecía propiamente ni a la comedia ni a la tragedia». Así, qué nueva comedia "pudo formar aquél [Lope de Vega] que se jactaba de desconocer y de despreciar el arte, de huir de la razón y de la regularidad y que trabajaba a destajo y sólo para contentar el capricho de un vulgo necio» (IV: 84-85).

En unos ańos en que el teatro barroco espańol estaba en alza, reconocido incluso por países extranjeros, leer una declaración de este tipo sorprende, máxime si es en un periódico considerado como españolista por Menéndez Pelayo. Es evidente que el periodista, en contra del emergente gusto romántico, reivindicativo del teatro barroco español, reconoce la superioridad del teatro francés y se muestra partidario de los principios neoclásicos, "universales», que los teóricos franceses habían conseguido imponer en toda Europa ${ }^{11}$.

Igual sucede cuando se compara el teatro clásico francés con el inglés. El primero es considerado como muy superior al de Shakespeare; así lo piensa Olive en el Memorial en su reseña de Otelo, donde critica a Mercier ( $D u$ théâtre) por su opinión al respecto: «Mercier, a quien un célebre crítico llama, y con sobrada razón, hereje en materias de gusto, tuvo la loca arrogancia de dar la preferencia a Shakespeare sobre Corneille y Racine, y aunque esta

según demostró René Andioc, 1999.

11. A pesar de ello, el periodista añade que ese teatro francés tan imitado, «no viene a ser otro que el de los griegos, con sólo las variaciones nacidas de la diversidad de costumbres de nuestras naciones modernas», un argumento -este sí, nacionalista- que las naciones europeas comenzaban a sostener contra el imperialismo cultural francés, defendiendo que el neoclasicismo francés, pretendidamente universal, no era más que una adaptación del clasicismo antiguo, porque «las reglas generales son las mismas y no pueden ser otras, pues la naturaleza es una y uno el arte que la imita; lo demás es desorden y desarreglo» (IV: 84). 
extravagante opinión arrastró a algunos incautos, cayó luego en el desprecio que merecía en una nación en donde tan universal es el buen gusto, principalmente en materias dramáticas». Continúa sosteniendo el periodista español que afortunadamente los «buenos críticos han formado del autor inglés el juicio que se merece», escritor de mucho ingenio, pero poco versado en «arte», al cual no se le debe «una sola composición arreglada», todas son «monstruosas, con algunas bellezas que de ningún modo resarcen sus muchos defectos» (III: 85).

Concluye Olive - de manera poco españolista- que los elogios tributados a Lope de Vega y a Shakespeare son injustificados, porque «el hombre de gusto no perdonará tal vez sus defectos por sus bellezas, y sólo leerá con verdadero placer y utilidad cierta las arregladas composiciones de un Racine. La riqueza de nuestro teatro, de que tanto se blasona, viene a ser una verdadera pobreza, porque es muy poco lo que en él se halla correcto y arreglado, y casi lo mismo podemos decir del inglés, aunque no hay duda que en estos últimos tiempos ha hecho mayores progresos»(III: 84-85). Así pues, reivindicación de ars frente a natura, en la línea del más paradigmático neoclasicismo.

A propósito de la extendida idea acerca de que el teatro barroco español fue imitado por los franceses del XVII, en la reseña a la traducción de García de Arrieta de los Principios de Batteux, opina el Memorial que «la verdadera gloria literaria no está en comenzar antes, sino en adelantar más». Que los franceses nos deban algunos pensamientos o ideas sueltas, o el argumento de alguna comedia, no impide que los autores galos de los reinados de Luis XIV y Luis XV fueran evidentemente superiores a los españoles. Acude al ejemplo del Cid de Corneille, y a sus deudas con Guillén de Castro, para concluir que el autor francés imitó a algunos autores españoles en sus obras medianas, pero a quien debe las sublimes bellezas de sus mejores obras, aquellas que "le han granjeado el sobrenombre del gran Corneille, es a su grande ingenio, ilustrado con el estudio de los griegos y de los latinos» (IV: 86). No se puede ser menos nacionalista; sobre todo teniendo en cuenta que en esta cuestión era comúnmente aceptado en España que tanto Corneille como muchos otros grandes autores franceses habían bebido en el teatro español del XVI y XVII y que gran parte de su mérito correspondía, por tanto, a los españoles. Concluye el periodista sosteniendo que el teatro francés es el primero, incluso el único, entre los modernos, y escribiendo que «si los franceses han llegado a elevarse a la par de los griegos y aun excederlos, como creen algunos, ha sido estudiándolos continuamente, imitándolos y aun copiándolos» (IV: 8588). El discurso nacionalista francés de Voltaire (El siglo de Luis XIV) y otros había calado profundamente en los pensadores españoles. 
También la pluma de Quintana se ocupa en Variedades de esta cuestión (a propósito de una nueva traducción de El Cid, de García Suelto): aunque reconoce en la obra de Guillén de Castro muchas bellezas, la admiración se convierte después en «indignación o en risa, al ver finalizar en monstruo disforme» lo que había empezado proporcionado y atractivo (I: 171). Se refiere Quintana a que el literato español convierte en tragicomedia lo que habría debido ser tragedia. Por el contrario, considera que las bellezas que Corneille «imitó y tradujo de la comedia española, unidas a las que su talento supo ańadir, causaron un entusiasmo general y hicieron una revolución en el teatro». Gracias a esta obra y a las posteriores (Horacio, Cinna, Polieucto, Pompeyo, Rodoguna...) de Corneille el teatro dio «un paso colosal» (I: 172175); se trata de «obras inmortales en que el arte se ve adelantado ya hacia la perfección, y donde aquel gran poeta dejó los rasgos y caracteres de una majestad, de una fuerza, y de una elevación que después no han sido igualadas de nadie». Como vemos, Quintana se adhiere a la idea de que Corneille fue uno de los creadores del teatro moderno, sin otorgar mayor importancia al supuesto origen español de ese nuevo teatro, algo que sí habían hecho los críticos de las dos últimas décadas del XVIII.

Pero la alta estimación que nuestros periodistas tienen del clasicismo de los franceses como maestros del arte dramático, se extiende también a otros géneros. En el ámbito de la novela, la reseña de Oderay (versión -casi traducción literal- de Zavala y Zamora de la novela anónima Oderahi, histoire americaine, de 1795) sirve a su autor (Mariano Carnerero en el Memorial) como pretexto para dibujar una panorámica de la novela moderna, y para sostener que Bernardin de Saint-Pierre es un excelente modelo en este género tan denostado hasta entonces. Tras explicar que las novelas europeas se reducían antes a intrigas amorosas o a sucesos terribles, lo que explicaba el deplorable estado en que se hallaba el género narrativo, "un hombre sencillo, un hombre observador, un hombre que conocía muy a fondo el corazón humano, en una palabra, Saint Pierre, publicó su Pablo y Virginia, obra maestra que tantas y tan dulces lágrimas ha arrancado a los corazones sensibles» (VI: 168-169) ${ }^{12}$. El periodista continúa su panegírico del escritor francés, afirmando que con esta novela acabó con las inverosimilitudes, las "descripciones insípidas, sucesos sombríos y lenguaje pomposo», ofreciendo a cambio orden en el planteamiento, bellas imágenes, lenguaje puro, amor

12. Por otra parte, el autor de la reseña sobre el cuento El inglés en la India se centra en elogiar a Saint Pierre por la moralidad de sus escritos: entre los autores franceses que destacan por «la belleza del estilo, la novedad y originalidad de las ideas, y en especial por aquel amor hacia los hombres en general, que forma la base de la moral pública, debemos contar a Bernardino de San Pedro» (V: 16). 
a la virtud, etc. ${ }^{13}$ Redondea su discurso sobre la novela moderna con un acentuado elogio de Chateaubriand y su Atala, novela excelente, "obra maestra en su clase», que coloca a similar altura que la de Saint Pierre: «no habrá nación alguna donde se aprecie la literatura que carezca de esta sublime producción del mismo autor de El genio del cristianismo». Las dos novelas citadas fueron sin duda -continúa el redactor- el modelo de muchas otras que se han escrito en Europa, como Oderay, motivo de la reseña, pero sólo motivo aparente porque en realidad el periodista se centra en disertar sobre el género narrativo y en elogiar la novela francesa (VI: 166-175).

También Olive afirmará que la historia de Pablo y Virginia es «una preciosa joya, es el más interesante y agradable cuento de cuantos los escritores de nuestros tiempos han compuesto» (V: 17). Variedades se ocupa igualmente de la nueva edición de Pablo y Virginia; el reseñador, José Miguel Alea, justifica el aprecio que se tiene a esta novela en toda Europa por su valor moral y literario. Él la considera un «modelo» como producción literaria, una obra "comparable y aun superior a lo mejor que se conoce en su género" (I: 57-58), lo que ha ocasionado que al «poco tiempo de haber salido a la luz» haya circulado "como una obra clásica por el mundo literario», siendo imitada por muchos autores europeos.

En el campo de la poesía, a propósito del fallecimiento de Saint Lambert, el Memorial Literario sostiene que el autor francés fue "poeta de los mejores del siglo que acaba de pasar, que competía con los buenos del anterior, y cuyo poema de las estaciones tienen algunos por igual y aun superior al de Thomson» (V: 22), suscribiendo después las elogiosas opiniones de La Harpe, quien considera Las estaciones de Saint Lambert «uno de los [poemas] que después de La Henriada han ennoblecido más la lengua francesa» (V: 25). El periodista también encomia los poemas en prosa y en verso suelto del autor francés.

A propósito de un libro educativo, Los viajes de Rolando y de sus compañeros de fortuna alrededor del mundo, de Jaufret, el redactor de Variedades (que firma como "Aa») escribe que "de todos los pueblos cultos de la tierra, los que más han poseído y poseen verdaderamente el arte de hacer los libros son los franceses. El orden, la claridad, el talento de despejar el objeto principal de todos los accesorios que pueden ofuscarle y de disponer los conocimientos de modo que, aunque sean cortos en número, por su oportunidad parezcan muchos, en fin, la habilidad de buscar las formas más agradables y más propias a interesar la atención y cautivar agradablemente el espíritu, son dotes

13. Todo ello a pesar de afirmar que las novelas sentimentales en general «fueron malas e indignas de aprecio y aceptación» (VI: 170). 
comunes a casi todos los autores franceses, y en que puede con seguridad decirse que no tienen rivales [...]. A este arte más que al mérito eminente de sus obras eminentemente clásicas, debe la literatura francesa la superioridad de que hoy goza» (I: 365-366).

En el ámbito de la lengua y de la retórica, el reseñador de la traducción española -de José Miguel Alea- del Tratado de los tropos de Du Marsais se felicita en Variedades de que por fin "las obras gramaticales de Du Marsais, tan apreciadas de todos los sabios de Europa, y de que carecíamos nosotros por efecto de una indolencia muy reprehensible», hayan sido trasladadas al español, «con el tino y precisión que se podía desear» (VI: 283).

José Miguel Alea es precisamente el autor de una reseña (IV: 166-178) en Variedades sobre los Sermones de E. S. Reybaz, precedidos de una carta sobre la retórica sagrada. Los comentarios del crítico español no pueden ser más elogiosos: «aun cuando no hubiera otra cosa en esta obra que la carta sobre el arte de la predicación, siempre ganaría mucho nuestra literatura con su publicación en castellano», pero además de los buenos preceptos contiene el «ejemplar vivo», los sermones del autor, con lo que «la ventaja de estas dos utilidades reunidas acaba de completar su mérito literario, y pide de justicia el extracto en un papel como el nuestro destinado a dar noticia de los libros útiles», los que "contribuyen a la propagación de las luces y del buen gusto».

\section{TRADUCCIONES}

Los comentarios acerca de la traducción, que tanto habían servido en las últimas décadas del XVIII para culpar a Francia de la decadencia de la lengua española, experimentan ahora un muy significativo cambio: suelen realizarse para constatar la ineptitud de los traductores espańoles, pero no para hacer comparaciones maniqueas y simplistas entre las dos lenguas. Es decir, en los periódicos que estudiamos ni la lengua francesa ni los autores franceses son considerados culpables de la decadencia de nuestra lengua y nuestra literatura.

El autor anónimo del "Juicio general del año cómico de 1801 y 1802», en el Memorial, considera que aunque las traducciones son de suma utilidad, puesto que así se enriquecen las naciones, «¿qué podemos esperar de las traducciones del día, hechas por gentes que parece aprendieron el castellano entre los gascones, y el francés entre los gallegos, sino la ruina total de nuestra lengua y literatura? Bien sabemos que el teatro francés es riquísimo en obras excelentes, mas no son las traducciones las que nos las 
dan a conocer, pues si alguna hay tal cual, las más son pésimas de puro malas». Así pues, concluye, no puede acusarse de bárbaro al público, ni de que aborrece la regularidad del arte, o de que halla fría la comedia francesa. Por el contrario, para el crítico, los bárbaros son los traductores, que «de tal modo estropean los bellos originales, que los mudan en monstruosas y horribles copias, y de esto ya hemos tenido repetidas pruebas, sobre todo en las traducciones de Molière, de Regnard, de Destouches, de Fabre d'Églantine y de Collin de Harleville, llenas de gracias en francés, de sandeces y desatinos en castellano. El público gusta por lo común de lo bueno, y creo que si se le diese una tragedia de Racine bien traducida, bien representada, bien decorada, la estimaría y la aplaudiría» (III: 56-57).

También se critica el que los traductores españoles recurran siempre a la versión francesa de cualquier obra de otra lengua que hayan de traducir: así, Olive considera lamentable que el traductor castellano de Otelo (Teodoro de Lacalle) se haya servido de una "mala traducción francesa» (de Ducis), por lo que la célebre obra de Shakespeare «más bien es un drama francés que inglés» (III: 85). Igual sucede en la reseña sobre Las estaciones, de Thomson, donde el crítico (F.E.) subraya que el lenguaje de esta traducción «es mestizo e impropio»; su traductor, "sin saber el inglés, a lo que parece, teniendo únicamente a la vista una mala traducción francesa y en prosa, y sin poseer el castellano cual se requiere para traducir y traducir en verso a Thompson, se ha metido en un trabajo que no pueden soportar sus débiles fuerzas» (III: 202-205).

Se consideraba, así pues, que cualquier traducción debía realizarse desde la lengua original, sin recurrir a la intermediación del francés. Munárriz se pronuncia sobre este particular en una carta a Variedades con la que adjunta su traducción del Ensayo sobre los placeres de la imaginación, de Addisson, "que años hace traduje del inglés. Ni entonces se me proporcionó, ni después he logrado ver la traducción francesa, aunque lo deseaba. Pero confío, no sé si con razón, en que no desmerecerá por esto mi trabajo, siempre que hubiese acertado a interpretar fielmente el original» (III: 27). Munárriz presume implícitamente de que él sí ha acudido directamente al inglés.

\section{Críticas a Francia}

No sería lógico ni verosímil esperar de nuestros periodistas sólo elogios hacia Francia, que, como vamos a ver, también recibe algunas críticas. Por lo que respecta al teatro, junto a esa gran estimación por el drama francés de los siglos XVII y XVIII, es frecuente hallar referencias al decaimiento 
que sufre en la Francia de los primeros años del XIX. En ningún caso es una crítica enconada, como las que realizaban tan frecuentemente nuestros autores dieciochescos. Ahora se acepta definitivamente la idea de que el clasicismo francés ha constituido un modelo indiscutible, que sólo ha empezado a descender de nivel en los últimos años. Así, el artículo titulado "Juicio general del año cómico de 1801 y 1802», del Memorial, afirma que «el teatro francés, en otro tiempo tan fecundo y tan excelente, en el día no presenta más que algunas composiciones que no pasan de la clase de juguetes agradables» (III: 61).

Otro crítico del Memorial señala que el teatro español podría corromperse aún más si no se seleccionan bien los muchos dramas franceses que se traducen a nuestra lengua. A pesar de ello, cuando compara nuestro teatro con el francés, subraya la «justa reputación que dieron al teatro de Francia los grandes ingenios que aquella nación produjo», de manera que las obras maestras de Racine o Molière deberían ser más admiradas por los españoles que nuestro propio teatro (IV: 204).

Los periodistas del Memorial también se permiten criticar a algunos importantes autores galos. Por ejemplo, Destouches es considerado como «uno de los primeros cómicos del siglo XVIII en el orden del tiempo y del mérito", pero muchas de sus comedias son de tan mal gusto que parece imposible que hubiesen sido escritas por el autor de obras tan excelentes como El vano humillado o El filósofo casado (III: 208). Beaumarchais, que recoge significativos elogios por El casamiento de Fígaro, es también criticado por la inmoralidad de su obra: «lo que él manejaba bien era la intriga, pero en cuanto a la moral, que es de lo que aquí se trata, no se le alcanzaba ni la teórica ni el estilo» (IV: 29).

Por otra parte, como tantas veces se hizo durante el siglo XVIII, el Memorial se queja de la escasa atención que los franceses ponen en las cosas de España, atreviéndose a enjuiciar nuestras obras y nuestra cultura sin haberse molestado en conocerla adecuadamente. Así, un anónimo redactor se lamenta de que la reseña que la Década filosófica francesa hiciera sobre la Historia critica de España del abate Masdeu anunciara al autor de esta obra como «Dom Demasdeux»; sólo este dato, continúa el periodista, demuestra que la obra está comentada y «anunciada con el mismo descuido con que regularmente se anuncian en Francia todas las nuestras» (V: 36).

En esta misma línea, el reseñador de la sátira Reflexiones de entre actos, hechas en la tragedia de Blanca o los Venecianos ${ }^{14}$ considera legítimo criticar las obras

14. Se trata de unas Reflexiones contra la tragedia Blanca y Montcasín, o Los venecianos (de Arnault, traducida por T. de la Calle), escritas por Juan Bautista Arriaza. 
foráneas, no sólo francesas, porque «una sátira contra una mala producción extranjera es una gota de agua para el océano de mofa y de desprecio en que ellos envuelven nuestra literatura, aun sin tener la curiosidad de investigarla» (IV: 202).

También Variedades se hace eco del desconocimiento de España que muchos autores franceses demuestran en las críticas a nuestro país. En la recensión a las Obras de Cadalso se escribe que «la ignorancia y la inconsideración con que por lo general hablan los franceses de nuestras cosas, son males incurables en ellos». Muchos de ellos equivocan "groseramente nuestros nombres, nuestros apellidos, nuestras instituciones y nuestras costumbres»; sin conocer nuestra lengua se ponen "gravemente a clasificar el mérito y graduación de nuestros poetas», etc. (I: 248-249).

Siguiendo esta opinión, Quintana publica en Variedades un trabajo titulado «Sobre un artículo de la Década filosófica» (III: 112-119), en el que a pesar de reconocer «el crédito que tan justamente tiene adquirido aquel interesante periódico", observa algunos errores y juicios injustos respecto de nuestra literatura a propósito de una traducción al francés de las fábulas literarias de Tomás de Iriarte. El articulista francés se refería a la esterilidad de la literatura española de los últimos años, comparada con la existente en la época de Cervantes, Lope, Calderón, etc.: "parece enteramente exhausta de escritores, o si los produce todavía, sus obras no pasan los Pirineos». Quintana responde que posiblemente es verdad que la literatura contemporánea no estaba en un buen momento, pero en los años en que Iriarte publicó sus fábulas [1782] «la actividad literaria estaba demasiado animada entre nosotros para merecer el concepto de nulidad que nuestro crítico le atribuye». En consecuencia, Quintana recomienda al redactor francés que se informe mejor, incluso limitándose a repasar las reseñas que sobre obras españolas se han publicado en los últimos años en la Década filosófica. Añade que si el periodista galo no sabe español -tal y como él mismo reconocía-, no posee la competencia necesaria para tachar de «insulsas» las fábulas de Iriarte. A pesar de todo, Quintana reconoce que Iriarte está «a una distancia inmensa de La Fontaine» y que carece de su sencillez y talento, pero posee suficientes méritos como "para que nadie se permita hablar de él con esa severidad desdeñosa». Como se ve, ni siquiera cuando elogia a la literatura española se permite Quintana despreciar a la francesa.

La crítica más severa a Francia que he hallado es la que hace el propio Quintana en unas reflexiones sobre la oposición entre la rima y el verso suelto (IV: 353-364). En su defensa del verso suelto, Quintana se ve obligado a responder a la supuesta opinión de los franceses, favorable a la rima: que los franceses sean partidarios de la rima «no es de extrañar, su lengua, pobre 
de inversiones, escasa de giros poéticos, absolutamente desnuda de armonía en comparación de las demás, necesita del artificio y el halago de la rima para hacer distinguir los versos de la prosa [...], pero nosotros los espańoles, con un idioma tan rico, tan vario en sus terminaciones, tan sonoro en sus sílabas [etc.], injuriamos a nuestra lengua si reputamos la rima como de absoluta necesidad en poesía». Vuelve a repetir, así, algunos de los tópicos que se habían manejado en el siglo anterior en el campo del paralelo de lenguas. Se trata de un argumento "histórico» que Quintana recupera dada su eficacia en la batalla que entonces sostenía contra el grupo de Moratín defensor de la rima y detractor del verso suelto.

Esta visión negativa acerca de la lengua francesa se repite en la reseńa de Variedades al Nuevo diccionario francés-español de Capmany (VIII: 114124). El anónimo crítico, quizás determinado por su intención de hacer una recensión favorable a Capmany, repite y suscribe los argumentos del autor catalán. Así, considera al francés "un idioma menos rico" que el español. Tras sostener que cada lengua tiene «su riqueza y pobreza respectivas", subraya que la nuestra aventaja a la francesa en «abundancia y variedad». Contra quienes proclaman que el idioma francés es más exacto y copioso que el nuestro para «las materias filosóficas y científicas», en cuya traducción advierten la inferioridad o esterilidad del castellano, sostiene que estos españoles confunden la «esterilidad de su cabeza con la de su lengua»; son ellos los culpables porque no saben buscar en nuestros libros las voces correspondientes. Sobre las nuevas "voces técnicas», niega que estas pertenezcan al francés; nuestros vecinos las han formado a partir del latín, algo que podríamos hacer también los españoles, pero nuestros autores no lo han hecho, y los franceses sí. Por ello concluye que quienes atribuyen al francés mayor riqueza, precisión y sabiduría, confunden «el lenguaje de los autores con el de la nación», con lo que, finalmente, está reconociendo la superioridad de los escritores franceses respecto a los nuestros. Se trata de una reseńa que se aparta del tono moderado del periódico, repitiendo la agresividad y algunos de los tópicos antigalos que circularon durante el siglo XVIII. La explicación quizás esté, como digo, en que el españolismo del libro de Capmany no permitía una reseña de otro tipo, si es que la intención del crítico era ser elogioso con Capmany, como fue el caso.

Finalmente, el único artículo que refleja el curso romántico que entonces tomaba el gusto literario y que, consiguientemente, supone una crítica leve al clasicismo francés, es el de Nicolás Böhl de Faber en Variedades, titulado «Reflexiones sobre la poesía». Allí se compara muy brevemente la aportación histórica que los distintos países han hecho a la literatura. Obviamente el autor alemán, defensor del nuevo gusto romántico no puede ser muy 
entusiasta con los franceses: «los franceses, aprovechándose de los españoles $\mathrm{y}$ de todos los que les antecedieron, limaron muchos géneros, pero su honesto idioma y casta imaginación no prestándose a los grandes efectos, únicamente han hecho algunos progresos en las encantadoras pinturas de las afecciones dulces y sociales». Por el contrario, su opinión respecto de otros países es más positiva: España posee "grandes cualidades y sublimes talentos»; los ingleses han conferido "toda la energía posible al idioma de la razón y del sentimiento", y los alemanes han conseguido que "todos los dioses del Olimpo bajen a sus hogares». Concluye así: «es preciso estimar sobremanera a los poetas españoles e italianos, divertirse con los rimadores franceses, admirar los bardos ingleses, y amar los romancistas alemanes» (VIII: 251-252). Los verbos aplicados a cada nación son muy elocuentes: divertirse, estimar, admirar y amar. En el escalón más bajo está Francia, y en el más alto, Alemania. Así fueron siempre los paralelos entre países. No podía ser de otro modo en un autor alemán y en aquellos años en que toda Europa quería desprenderse de la anterior hegemonía cultural francesa. En cualquier caso, este artículo no sigue la línea general de los periódicos que comentamos, mucho más admirativa con la literatura y cultura francesas, tal y como hemos querido demostrar.

Podemos asegurar, concluyendo, que la imagen de Francia en Variedades y en el Memorial de aquellos años es enormemente positiva. En ninguno de los dos periódicos se aprecia el tan frecuente y socorrido maniqueísmo nacionalista de muchos críticos españoles del siglo XVIII. Asimismo, ninguna de las dos publicaciones es anglófila. Los críticos literarios de ambos periódicos realizan sus juicios desde la perspectiva teórica del pensamiento neoclásico. La consecuencia de todo ello es un predominante tono francófilo, concretado en una apología de los autores clasicistas franceses de los siglos XVII y XVIII. En el ámbito de la teoría y la crítica literarias, La Harpe, Marmontel y la Década Filosófica son muy admirados y seguidos por nuestros periodistas, que se olvidan de los tratadistas españoles para abrazar las opiniones de teóricos clasicistas galos. En consonancia con esto, las opiniones sobre la traducción de obras francesas también se invierten con respecto a las dos últimas décadas del siglo: ahora se piensa mayoritariamente que si existen malas traducciones no es por culpa de la lengua de origen, el francés, ni de los autores franceses originales -considerados ahora como superiores a los españoles-, sino de los malos traductores españoles.

En el campo del teatro se proponen como modelos máximos a Racine, Molière, Voltaire y Corneille (este con menor unanimidad); un escalón más abajo se coloca a Legouvé, Destouches, Beaumarchais, etc. Los paradigmas en 
el ámbito de la novela son Bernardin de Saint-Pierre y Chateaubriand. Saint Lambert es el modelo propuesto para la lírica. Existen significativos elogios, además, para autores de otras disciplinas; destaquemos a Du Marsais, como gramático. Las únicas censuras que recibe Francia son relativas a los libros que allí se estaban publicando en los últimos años.

Las disensiones entre los dos periódicos son mínimas: rima frente a verso suelto, Moratín o Quintana como modelos dramáticos, y algunas otras leves discrepancias que para nada afectan a la cuestión de los modelos franceses. Aunque esta prensa fuese órgano de expresión de quintanistas y moratinistas, lo cierto es que unos y otros coinciden en el elogio de los autores clásicos franceses. Esto corrobora que las opiniones de ambos periódicos pertenecen a la órbita del pensamiento neoclásico, aunque en Variedades se perciban ciertos matices de «neoclasicismo heterodoxo» (Checa Beltrán: 1998, págs. 283-310).

Esta admiración por los autores clasicistas franceses significa un vuelco en relación con la actitud predominantemente crítica de las dos décadas anteriores. Quien esté familiarizado con la lectura de publicaciones españolas de los años 80 y 90 del XVIII no podrá más que sorprenderse al comprobar que el gusto y la admiración por la literatura francesa se han recuperado después de unos años en que lo francés fue tan denigrado. Pocas veces durante el siglo XVIII se manifestó de manera tan abierta y entusiasta la admiración española por la literatura francesa. La alianza política hispano-francesa de los primeros ańos del XIX seguramente tuvo bastante que ver con la evidente francofilia de estos dos periódicos españoles. Y es que el canon literario no es ajeno a ideologías y a estrategias políticas coyunturales.

\section{BibliografíA}

Alcalá Galiano, Antonio, Recuerdos de un anciano, Madrid, Librería de Perlado, Páez y Cía, 1913.

Andioc, René,, «El Teatro Nuevo Español, ¿antiespañol ?», Dieciocho, 22.2, 1999, págs. 351-372.

- y Coulon, Mireille, Cartelera teatral madrileña del siglo XVIII (1708-1808), Toulouse, Presses Universitaires du Mirail, 2 vols. (Anejos de Criticón, 7), 1996. Aymes, Jean-René (ed.), La imagen de Francia en España durante la segunda mitad del siglo XVIII, Alicante, Instituto Juan Gil-Albert y Presses de la Sorbonne Nouvelle, 1996.

- y Fernández Sebastián, Javier (eds.), La imagen de Francia en España (18081850), Bilbao, Universidad del País Vasco / París, Presses de la Sorbonne Nouvelle, 1997. 
Checa Beltrán, José, "Teoría literaria», en Historia literaria de España en el siglo XVIII, ed. de F. Aguilar Piñal, Trotta-CSIC, 1996, págs. 427-511.

- Razones del buen gusto. Poética española del neoclasicismo, Madrid, CSIC, 1998.

- «En busca del canon perdido. El siglo XVIII», Studi Ispanici, LXII, 124, 2002, págs. 317-326.

- Pensamiento literario del siglo XVIII español. Antología comentada, Madrid, CSIC, 2004.

Estala, Pedro, Edipo tirano, tragedia de Sófocles, traducida del griego en verso castellano, con un discurso preliminar sobre la tragedia antigua y moderna, Madrid, Sancha, 1793.

García de Villanueva y Parra, Manuel, Origen, épocas y progresos del teatro español, Madrid, Gabriel de Sancha, 1802.

Larriba, Elisabel, Le public de la presse en Espagne à la fin du XVIII siècle (17811808), París, Honoré Champion, 1998.

Le Gentil, Georges, Les revues littéraires de l'Espagne pendant la première moitié du XIXe siècle: aperçu bibliographique, París, Hachette, 1909.

Lopez, François, Juan Pablo Corner (1756-1797) y la crisis de la conciencia española, Salamanca, Junta de Castilla y León. (Primera edición: Juan Pablo Forner et la crise de la conscience espagnole au XVIII siècle, Bordeaux, Institut d'Études Ibériques, 1976), 1999.

- «La institución de los géneros literarios en la España del siglo XVIII», Bulletin Hispanique, CII, 2, 2000, págs. 473-517.

Menéndez Pelayo, Marcelino, Historia de las ideas estéticas en España, Madrid, CSIC, 2 vols., 1974.

Moreno Alonso, Manuel, La forja del liberalismo en España. Los amigos españoles de Lord Holland, 1793-1840, Madrid, Congreso de los Diputados, 1997.

Quintana, Manuel José, Obras completas, BAE, 19, Madrid, Atlas, 1946.

Ríos Carratalá, J. A., «Destouches en España (1700-1835)», Cuadernos de traducción e interpretación, 8-9, 1987, págs. 257-265.

Rodríguez Sánchez de León, María José, La crítica dramática en España (17891833), Madrid, CSIC, 1999.

Urzainqui, Inmaculada, «Batteux español», en Imágenes de Francia en las letras hispánicas», Barcelona PPU, 1989, págs. 239-260.

- «Los redactores del Memorial Literario (1784-1808)», Estudios de Historia social, 52-53, 1990, págs. 501-516.

- "Poética teatral. Presencia y prestigio de los críticos extranjeros», en El teatro europeo en la España del siglo XVIII, (ed. de Francisco Lafarga), Lleida, Universitat de Lleida, 1997, págs. 15-59.

Vargas Ponce, José, Declamación contra los abusos introducidos en el castellano, Madrid, Viuda de Ibarra, 1793. 